\title{
As grandes marcas na pequena Parintins: Um estudo sobre a adaptação do discurso da marca global ao regional como estratégia de comunicação
}

\author{
The major brands in the small Parintins: \\ A study about the speech's adaptation from global \\ to local as brand communication strategy \\ por Rafaela Claudia Sotuyo e Gabriela B. Mager
}

\section{RESUMO}

Dentro de uma sociedade permeada pelo contexto midiático, o design gráfico - como atividade ligada à produção e difusão de significações por meio de textos e imagens - contribui para a criação de percepções e ideologias e é parte integrante da cultura contemporânea. Este artigo propõe uma discussão acerca da relação entre contextos culturais, identidades e estratégias de comunicação de marca. Para isso, analisa o Festival Folclórico de Parintins e estuda as estratégias utilizadas pelas marcas para participar e referenciar a cultura local e os impactos dessas ações na realidade econômica das marcas e da região.

Palavras-chave Design Gráfico; Marcas; Identidade Cultural

\section{ABSTRACT}

Within a society permeated by the media context, graphic design - as an activity linked to production and diffusion of meaning through text and images - contributes for the creation of perceptions and ideologies and is an integral part of contemporary culture. This paper proposes a discussion about the relationship between cultural contexts, identities and brand communication strategies. For this, the present research analyses the Parintins Folk Festival and studies the strategies used by the brands to participate and refer the local culture and the impact of these actions on the economic reality of the brands and the region.

Keywords Graphic Design; Brands; Cultural Identity 


\section{Introdução}

Nas últimas décadas, as marcas adentraram o cotidiano das pessoas a ponto de ser praticamente impossível não conviver com elas. Marcas têm o poder de comunicar, contar histórias e fomentar desejos. Conseguem, ainda, vencer barreiras geográficas e culturais e penetrar nos mais diversos contextos sociais, influenciando hábitos de consumo, ideologias e estilos de vida.

No cenário atual em que marcas globais se dirigem a diversas culturas e países de uma só vez, a preocupação com variáveis que dizem respeito à compreensão de significados se tornou uma realidade dentro do planejamento estratégico de discurso das marcas.

Mediando informações entre diferentes narrativas sociais, o design gráfico articula discursos que se inserem na realidade das pessoas e contribuem para a formação e transformação de idéias e comportamentos, permitindo que os diferentes contextos socioculturais interfiram em suas estratégias de comunicação. Como é o caso de algumas marcas, como Coca-Cola, McDonald's, TIM ou Unilever, que além de moldar hábitos de consumo, ideologias e estilos de vida, adaptam seus próprios discursos globais às particularidades de determinadas localidades.

Por compreender a prática do design gráfico como importante articuladora no processo de gestão das marcas capaz de influenciar, interconectar e transformar ideias e significações socioculturais, este artigo propõe, partindo da dualidade entre o mundo globalizado e as identidades locais, uma reflexão acerca da atuação das marcas globais dentro de mercados localizados, com o intuito de compreender como seus discursos se articulam nas diferentes narrativas sociais.

A comunicação das marcas é desenvolvida, principalmente, por designers, publicitários, jornalistas e profissionais de marketing. São ações estrategicamente planejadas para que os valores e posicionamento da marca gerem associações positivas no imaginário dos indivíduos, cujo resultado esperado é a construção de um elo entre marca, indivíduo e grupos sociais.

Por meio de um estudo de caso que pudesse representar este fenômeno, escoIhemos analisar as estratégias de comunicação das marcas na região de Parintins para identificar os possíveis reflexos dessas ações na realidade das marcas e no contexto local.

\section{0 contexto moderno e as identidades culturais}

A mudança na experiência do tempo e do espaço, resultante das transformações modernas, afetou o modo como as pessoas percebem o mundo. A aceleração dos processos temporais, propiciada pela expansão do capitalismo e o desenvolvimento de novas tecnologias nos transportes e meios de comunicação, 
venceu barreiras espaciais a ponto de tornar o mundo pequeno aos olhos humanos. A compressão espaço-tempo percebida na modernidade', principalmente em função do processo de globalização, permitiu que os acontecimentos de um determinado local possuíssem impacto imediato sobre indivíduos e lugares situados a grandes distâncias. Esse imediatismo proporcionado, sobretudo pelas mídias, verificado na vida moderna, não tornou globais apenas notícias de fatos localizados, mas também, estilos de vida, comportamentos culturais, tendências de consumo, marcas, produtos, imagens e uma infinidade de outros dados que repercutem na compreensão de vida e mundo.

Mesmo não ocorrendo de forma homogênea, o processo de globalização expõe as pessoas a diversos contextos culturais, como afirma Canclini (2003), fazendo com que os indivíduos se deparem com a noção do outro e com diferentes percepções de mundo que interferem diretamente no modo como as identidades culturais se constituem. A complexidade das experiências e relações vividas em tempos globais faz com que as identidades permaneçam em contínuo processo de formação e transformação. Ao estarem relacionadas com processos de significação e representação cambiantes, as identidades culturais contemporâneas se tornam também mutáveis e adaptáveis (HALL, 2006).

Uma vez que se considera que a identidade é construída com base no contexto cultural, entendido como a fonte de significados e experiências de um povo (CASTELLS, 2003) e que a linguagem midiática, dominada pelas imagens, tem um papel fundamental na produção de discursos que moldam os modos de vida atuais, pode-se concluir que as esferas vinculadas à produção e à disseminação de imagens fazem parte da construção da identidade cultural dos indivíduos na contemporaneidade. 0 design gráfico, como prática comunicativa ligada aos processos de produção, circulação e consumo de significações por meio de textos e imagens, fala do contexto cultural em que está inserido ao mesmo tempo em que faz parte dele, 0 alimenta e contribui para sua transformação (VILLAS-BOAS, 2002).

Para Forty (2007), o design gráfico é um dos grandes expoentes das mídias atuais e exerce forte influência na forma como as pessoas constroem pensamentos, se comportam e se localizam em sociedade. 0 seguinte tópico propõe um aprofundamento das práticas do design gráfico, principalmente no que diz respeito às marcas, com o fim de compreender como seus discursos se articulam nos diferentes contextos culturais.

1 David Harvey (1994) discorre sobre a relação espaço e tempo como determinante para a percepção de realidade pelos grupos sociais em diferentes contextos. 


\section{0 olhar social sobre o design gráfico e as marcas}

0 intenso processo de industrialização vivido na sociedade ocidental ao longo dos séculos XIX e XX e o avanço da economia capitalista, afetaram de maneira decisiva os modos de vida ocidentais, moldando uma sociedade moderna que tem o consumo como comportamento padrão. Sob o ponto de vista do design, pode-se dizer que este é fruto desse contexto: da sociedade industrial, da cultura de massas e do fetiche pela mercadoria. 0 design é uma atividade diretamente ligada ao sistema capitalista e à transmissão de idéias e, portanto, possui um papel fundamental na criação da riqueza industrial e na formação de percepções e juízos de valor (FORTY, 2007). Além disso, o design é parte significativa de nossa cultura, pois "configura a comunicação e cria identidades" (SCHNEIDER, 2010: 09).

No que diz respeito às marcas, sua onipresença na sociedade contemporânea é praticamente incontestável. Assim como as imagens, as marcas estão por todos os lados, em embalagens, cartazes, roupas, prédios, carros, vitrines, revistas e numa série de outros suportes com os quais as pessoas se deparam diariamente. Mas quais são suas funções e por que são tão presentes no cotidiano moderno? Para discutir o papel desempenhado pelas marcas dentro da sociedade contemporânea, é válido compreender como ocorreu a transformação de suas funções no decorrer do avanço da economia capitalista.

Costa (2008) e Semprini (2006) apresentam e analisam a evolução histórica das marcas, que nasceram por razões meramente utilitárias nas primeiras trocas comerciais, ainda na Antigüidade, quando tinham a única função de identificar a origem das mercadorias. Posteriormente, no contexto de produção em massa e forte concorrência causados pelo processo de industrialização do século XVIII, além de identificar a procedência dos produtos, as marcas passam a promover e ressaltar suas qualidades na tentativa de atrair os consumidores e vencer os concorrentes. No início do século XX, as marcas adquirem autonomia em relação ao produto/ serviço e se tornam o signo de identidade das empresas. Nesse contexto, mais do que por seus produtos e serviços, as empresas passam a ser distinguidas por seus nomes e suas imagens.

Na segunda metade do século XX, a marca se torna, por si só, um objeto de desejo, em que já não interessa tanto a vantagem de determinado produto, mas o discurso por trás da marca desse produto, o que ela diz e o que representa socialmente, a sua imagem (SEMPRINI, 2006).

Assim, no caso das marcas, se consome muito mais pelo significado, do que pelo uso prático. A experiência senso-emocional buscada pelos indivíduos ao comprar determinadas marcas é parte da mudança de paradigma com relação às expectativas do consumidor. Espera-se que a marca seja, antes de tudo, uma emoção (COSTA, 2008). Esse panorama evidencia o caráter desmaterializado do consumo contemporâneo, no qual o que se consome são experiências, emoções, idéias, imaginários, conteúdos e histórias (SEMPRINI, 2006). 
A mudança de paradigma vivenciada no consumo faz com que as marcas penetrem no espaço social, a fim de tecer laços emocionais com seus consumidores. ou seja, as marcas ultrapassam as fronteiras do consumo para investir no espaço social e se vincular cada vez mais às paixões e preocupações de seus consumidores e contribuir para a atribuição de valores e sentidos às suas vidas. Programas de patrocínio, projetos de desenvolvimento econômico e social e campanhas de ajuda humanitária são algumas das ações encabeçadas pelas grandes marcas nas diversas esferas da vida social.

Para Semprini (2006), dentro de um espaço social dominado pela imaterialidade e pelos significados, as marcas se articulam dentro da lógica de construção de mundos possíveis, que alimentam o imaginário coletivo e convidam os indivíduos a experimentar seus universos. A intenção das marcas é articular discursos que façam sentindo para os indivíduos e que os ajudem a alimentar suas identidades e dar significado às suas experiências.

Naomi Klein (2003) critica o poder das marcas e afirma que, historicamente, elas se tornaram globais e impuseram a diferentes culturas seus discursos únicos, que não conversavam com as diferenças culturais. De acordo com Semprini (2006), cada destinatário absorve as mensagens da marca de acordo com sua perspectiva e suas expectativas pessoais, e ainda, busca mundos possíveis mais próximos de sua cultura, vinculados ao seu estilo de vida e gosto pessoal. Nos últimos anos, observam-se algumas marcas atrelando seus discursos aos valores socioculturais e aos modos de vida de seus receptores de modo a conferir-lhes um tratamento quase personalizado. A customização também entra no fluxo estandardizado da marca, mas a percepção gerada é de que o atendimento é individualizado.

Para exemplificar o fenômeno da atuação de grandes marcas em contextos regionais, abordaremos as estratégias de comunicação de algumas marcas dentro da realidade sociocultural do Festival Folclórico de Parintins, com o fim de discutir de que maneira seus discursos globais se articulam às particularidades da cultura local, resultando em uma comunicação dita "customizada".

\section{Caso Parintins}

0 Festival Folclórico de Parintins transforma a pequena cidade de Parintins, no Amazonas, no palco da mais importante manifestação cultural do Norte brasileiro. Durante três dias de festa, a cidade se vê dividia em duas fanáticas torcidas que acompanham a competição entre as duas agremiações locais de Bois Bumbás: 0 Boi Garantido, representado pela cor vermelha e cujo símbolo é um coração, e o Boi Caprichoso, de cor azul e que tem como símbolo uma estrela. A disputa entre os bois ocorre no Bumbódromo, um estádio igualmente dividido em setores de cor azul e vermelha que foi construído especialmente para abrigar a festa. 
No período festivo, a cidade de Parintins atrai milhares de turistas, fazendo com que o número de indivíduos na cidade, de pouco mais de 100 mil habitantes, praticamente duplique. Além da rica manifestação cultural envolvida nas apresentações que exploram temas regionais (lendas, rituais indígenas e costumes ribeirinhos), os turistas também são cativados pelo espetáculo da rivalidade entre as torcidas. Uma rivalidade cheia de história e respeito, que envolve uma série de regras e peculiaridades. 0 nome do boi rival, por exemplo, jamais é mencionado entre os torcedores, que preferem referir-se ao adversário como "o contrário". 0 fanatismo é tanto que as torcidas se recusam a utilizar ou consumir qualquer coisa que seja na cor do boi rival.

O festival é uma poderosa manifestação da cultura regional, através da qual, a cidade de Parintins expressa sua identidade para o Brasil e o mundo (CAVALCAN$\mathrm{TI}, 2000$ ). Com o passar dos anos, a festa foi conquistando importantes parcerias e patrocínios, que além de ajuda financeira, garantem uma maior divulgação do evento.

A Coca-Cola Brasil, que desde 1995 apóia o evento, é a mais antiga patrocinadora do festival. Desde o início dessa parceria, a empresa trata de ir além da ajuda financeira aos bois, promovendo o festival a nível nacional e internacional. Assim, propaga e colabora com o aumento do turismo e com o desenvolvimento cultural, econômico e social da região; além de ampliar sua venda e se tornar mais valorizada, mesmo que o discurso de marca não demonstre essa intenção.

Muito mais do que divulgar a sua marca, a Coca-Cola Brasil tem a intenção de se atrelar aos costumes regionais. Para se integrar à manifestação cultural parintinense, a empresa deixou de ser apenas a "patrocinadora oficial" para tornar-se uma "grande torcedora". Durante quase dez anos a marca tentou ficar alheia à rivalidade das torcidas, mas a sua cor vermelha característica não conseguiu frear as críticas Caprichosas. Por isso, em 2005 a Coca-Cola Brasil decidiu abrir uma rara exceção e lançou uma versão azul de sua marca. Essa façanha possibilitou a Coca- Cola torcer também do lado Caprichoso do Bumbódromo e participar da festa de maneira integral.

A partir de 2005, a famosa rivalidade parintinense passa a ser explorada de fato na comunicação da Coca-Cola. Com a frase "É preciso dois contrários para a festa ficar completa", a marca torna a disputa entre os bois o principal atrativo de sua campanha em Parintins. Para ressaltar ainda mais os dois lados, a maioria das peças gráficas ficam literalmente dividas ao meio, os azuis de um lado e os vermelhos do outro, como todo o resto da cidade em época de festival.

0 fato das torcidas não aceitarem nada na cor rival repercutiu também na venda das latinhas de Coca-Cola, tipicamente vermelhas. Então, para possibilitar aos torcedores Caprichosos o consumo de Coca-Cola sem correr o risco de se render ao lado Garantido, a empresa lançou, ainda em 2005, uma latinha inteiramente azul. 
As grandes marcas na pequena Parintins:

Um estudo sobre a adaptação do discurso da marca

global ao regional como estratégia de comunicação

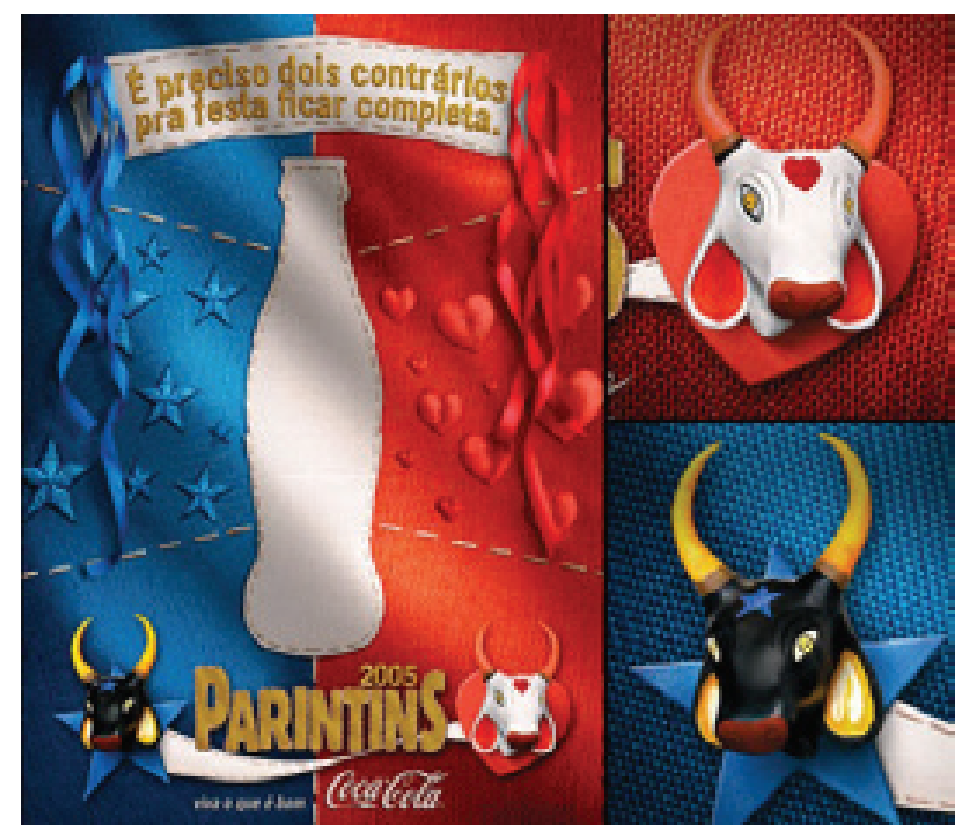

Figura 1 - Peça Gráfica da Coca-Cola para o Festival Folclórico de Parintins de 2005. Disponivel em: http://www.designatento.com/images/stories/dge/08_09_19_coca01.jpg Acesso em: 17 de maio de 2011.
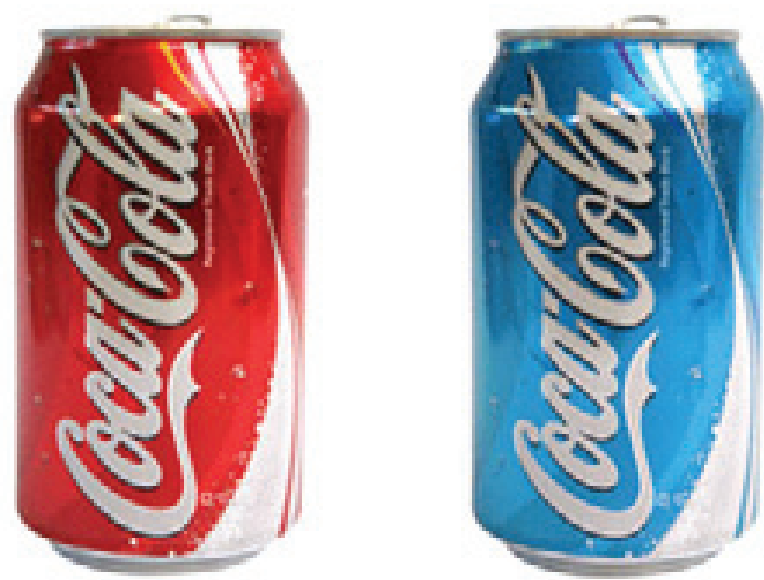

Figura 2 - Latas de Coca-Cola vermelha e azul

Disponível em: 〈http://lucasafonso.blogspot.com/2009/05/parintins-2009-coca-cola-azul-para.html〉 Acesso em: 17 de maio de 2011.

Em 2007, enquanto a Coca-Cola dizia para o mundo: "Viva o lado Coca-Cola da vida", em Parintins, a empresa lançava a campanha: "Viva o lado Coca-Cola dos Bumbás", numa alusão à importância que os Bois Bumbás têm na vida das pessoas da região. Tratando de se vincular cada vez mais ao festejo local, a marca faz com que a festa se origine na própria garrafa de Coca-Cola, de onde saem os bois e o todo o brilho do Festival. 0 mesmo acontece na campanha de 2008. 

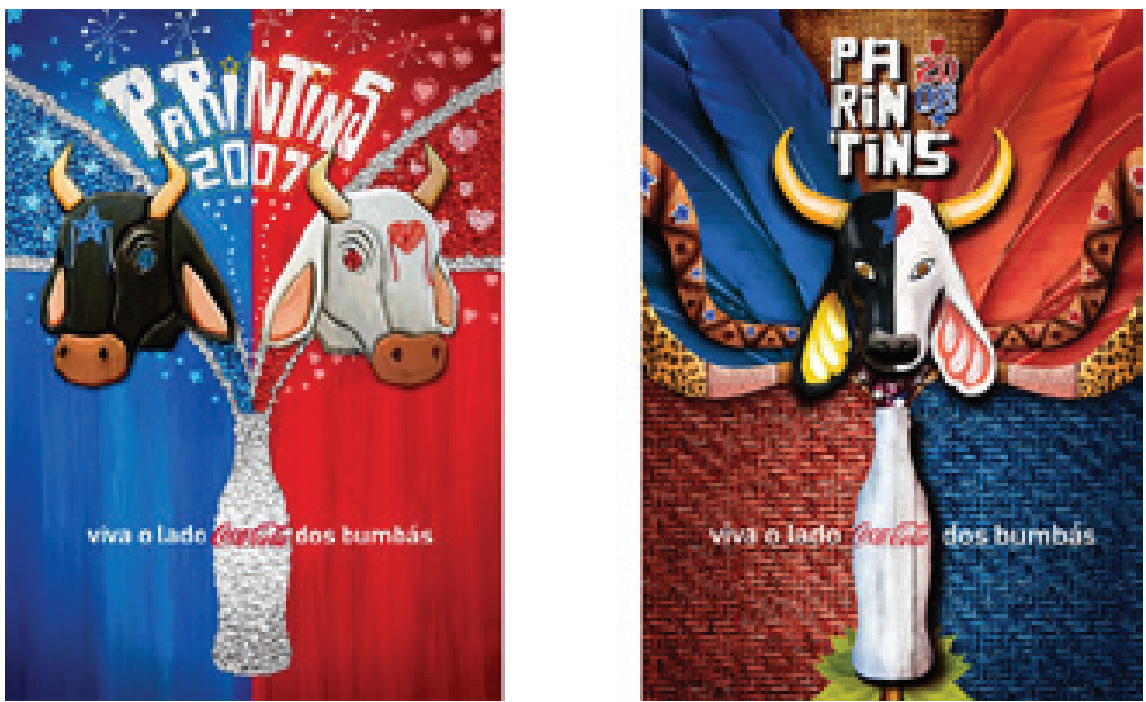

Figura 3 - À esquerda, cartaz da Coca-Cola para o Festival Folclórico de Parintins de 2007. Disponível em: http://behance.vo.Ilnwd.net/profiles/75546/projects/103052/ 755461214509796.jpg. Acesso em: 17 de maio de 2011.

Figura 4 - À direita, cartaz da Coca-Cola para o Festival Folclórico de Parintins de 2008. Disponível em: 〈http://logobr.wordpress.com/2008/09/17/coca-cola-azul-parintins/> Acesso em 17 de maio de 2011.

Em 2009, para reforçar o vínculo emocional com o festival, a Coca-Cola lançou um vídeo em comemoração aos quinze anos de parceria. Na campanha de 2010, ao invés de ser o elemento que origina o festejo, a garrafa de Coca-Cola aparece incorporada à cesta de "Parintins 2010", junto de outros elementos representativos da cultura local, como plumas, artesanato, folhas, flores e frutas. Figurando como mais um componente identitário da cultura parintinense, a Coca-Cola reafirma seu forte envolvimento com o local.

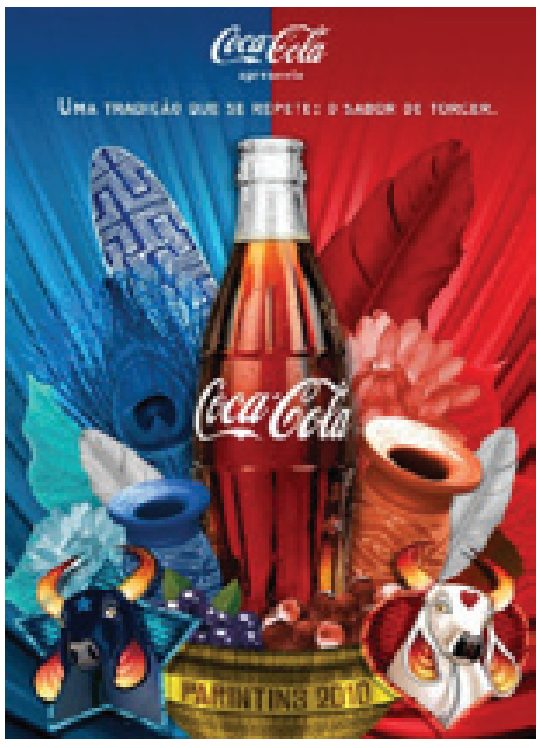

Figura 5 - Cartaz da Coca-Cola para o Festival Folclórico de Parintins de 2010.

Disponivel em: http://www.pdvnews.info/2010/06/coca-cola-em-parintins-2010.html

Acesso em: 19 de maio de 2011. 
As grandes marcas na pequena Parintins:

Um estudo sobre a adaptação do discurso da marca global ao regional como estratégia de comunicação

Naomi Klein (2003) acredita que quando uma marca apóia um evento cultural, muitas vezes acaba deixando de ser apenas patrocinadora e se transforma na própria cultura, ou seja, ela se insere na linguagem cultural a tal ponto, que termina se fundindo nela. Seguindo essa lógica e observando as ações da Coca-Cola dentro do Festival Folclórico de Parintins, é possível notar que a marca tenta passar por esse processo, quer dizer, a Coca-Cola quer ser Parintins, ser a festa, o folclore, as torcidas, o Garantido, o Caprichoso, e todos os demais elementos e valores intrínsecos nessa manifestação cultural. A Coca-Cola quer se tornar um elemento da cultura local e mostrar que sem ela a festa não está completa. Esse é o discurso que a marca lança como estratégia de controle do mercado local, impedindo o crescimento de marcas concorrentes.

As ações da Coca-Cola em Parintins serviram de exemplo para muitas outras empresas, que também lançaram versões de suas marcas em outras cores e até produtos comemorativos exclusivos para festival. Além da Coca-Cola, apóiam os bois: Kaiser, Band, Bradesco, Petrobrás, Eletrobrás, Natura, Nestlé, Correios, TRIP Linhas Aéreas, Secretaria do Estado e da Cultura (SEC), Prefeitura de Parintins e Governo do Estado do Amazonas.

Além das adaptações de grande parte dessas marcas, empresas como a Nestlé e a Natura lançaram produtos comemorativos exclusivos do festival. No caso da Nestlé, a embalagem especial da Ninho Parintins (figura 6) foi vendida por toda a região Norte, enquanto que a linha Natura Ekos Festas do Brasil ópera Amazônica (figura 7) foi comercializada por todo o Brasil. Ao lançar produtos comemorativos do festival, as empresas propagam estar celebrando e difundindo as tradições locais.
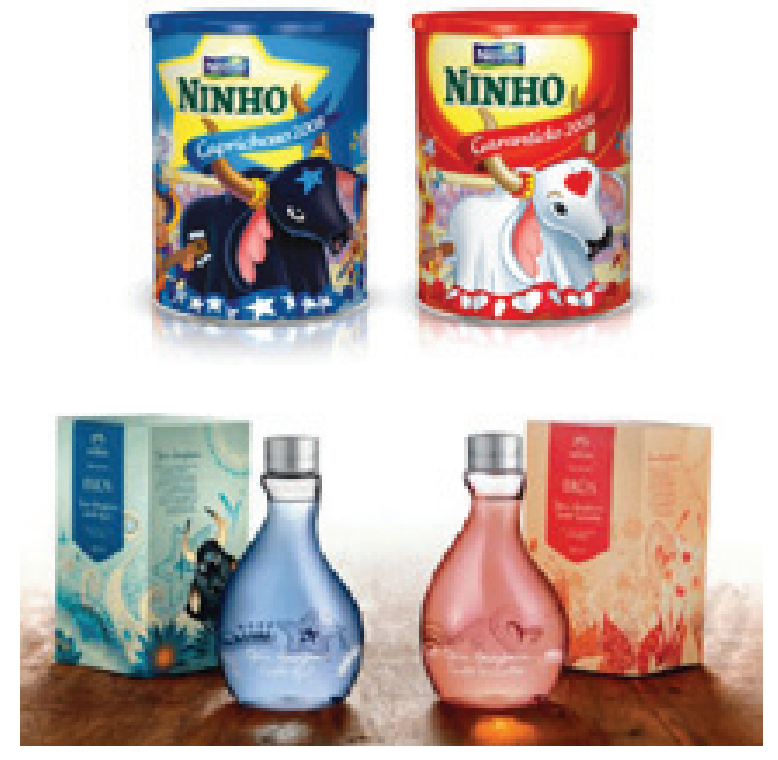

Figura 6 - À esquerda, embalagens Ninho Parintins 2008.

Disponivel em: 〈http://www.pande.com. br/expertise_interno.php?tipo=clidtid_ cli=38ctid_job=16> Acesso em: 23 de maio de 2011.

Figura 7 - À direita, águas de banho Natura Ekos Festas do Brasil ópera Amazônica. Disponivel em: 〈http://revendonatura.blogspot.com/2010/07/edicao-limitada.html> Acesso em: 23 de agosto de 2011. 
Algumas marcas, mesmo sem patrocinar o Festival Folclórico de Parintins, lançam campanhas e produtos inspirados nessa grande manifestação cultural, como é o caso da Adidas, que lançou um tênis exclusivo em homenagem à festa de Parintins. A edição fez parte da série "Flavours of the World" , que lançou modelos limitados inspirados em diferentes feriados e manifestações culturais ao redor do mundo. Ao convidar as pessoas a experimentar outras culturas através de seus produtos temáticos, a Adidas, assim como a Nestlé e a Natura, se apropria da diversidade e confirma a tendência, apontada por Naomi Klein (2003), que as grandes marcas têm de comercializar a diferença e utilizá-la a seu favor. Se a regra para o mercado atual for: quanto mais diversificado e inusitado, melhor; o Festival Folclórico de Parintins - com todos os seus costumes e particularidades - é um prato cheio para quem quer investir na comercialização da alteridade.

Além da exploração comercial da diferença, é possível perceber outra tendência das marcas que atuam em Parintins, que é a de penetrar no espaço social a fim de tecer laços emocionais com as pessoas locais. Ao patrocinar o festival, as marcas vão além da divulgação de seus produtos e serviços para se vincularem diretamente à paixão local pelas tradições.

Ademais da preocupação de se fazer presente durante o festejo, nota-se o empenho das marcas em captar as particularidades culturais da região - os costumes, os valores, as perspectivas e os estilos de vida - para direcionar seus discursos à realidade local e atender as expectativas de todos os consumidores. Em um mercado dominado pela lógica do capitalismo, é de se esperar que nenhum investimento seja em vão. Em um primeiro momento, todas essas ações aparentam respeito pela cultura local. Entretanto, é ingênuo crer que uma empresa que investe milhões de reais para apoiar um festival regional esteja interessada apenas em contribuir para o seu desenvolvimento e em disseminar sua diversidade cultural. 0 fato é que as empresas investem o que investem e adaptam seus discursos à realidade local justamente por visualizarem o enorme potencial econômico da festa e o retorno financeiro que podem obter através dessas ações.

Mas é importante reconhecer, que mesmo que os investimentos das grandes empresas aconteçam por interesses meramente econômicos, é interessante para o festival que essas parcerias existam. Querendo ou não, as grandes marcas contribuem com o crescimento e disseminação da festa, e acabam motivando o aumento do turismo e o desenvolvimento econômico da região como um todo. Além disso, os meios de comunicação divulgam a curiosa rivalidade entre Garantido e Caprichoso e permitem que as ações feitas pelas grandes marcas para se adaptar a realidade local se tornem conhecidas em outras localidades, ajudando a fomentar o desejo das pessoas de presenciar de perto todos esses acontecimentos.

2 Sabores do mundo. (tradução livre) 
As grandes marcas na pequena Parintins:

Um estudo sobre a adaptação do discurso da marca

global ao regional como estratégia de comunicação

\section{Considerações Finais}

Na sociedade contemporânea, o design gráfico atua como agente formador e transformador e possibilita a troca de fatos, experiências e outras informações que implicam na maneira de perceber e encarar o mundo. No que diz respeito às marcas, foi possível perceber a transformação mútua entre estas e a sociedade: ao mesmo tempo em que as marcas são capazes de modificar a realidade, o contexto é capaz de moldar a maneira como as marcas se comunicam. A comunicação das marcas demonstra que o olhar sobre os regionalismos está em evidência. Os discursos são criados para que a sociedade perceba as marcas como instituições que respeitam a cultura. Observamos que esta é uma nova estratégia para manter e ampliar os vínculos de identidade entre marcas e indivíduos.

Infelizmente, no âmbito do design, atividade importante para a construção da imagem de marca, essas relações não são tão discutidas quanto deveriam. Falta perceber e discutir as funções sociais da marca e sua capacidade de transformar a realidade.

Os novos paradigmas pontuados nesta pesquisa evidenciaram a importância de questionar e debater o papel do design dentro da sociedade contemporânea. Também é fundamental que os designers, enquanto profissionais e pesquisadores, adotem uma postura mais crítica e consciente acerca da abrangência de suas atividades e da responsabilidade envolvida em contestar e transformar as realidades do mundo atual. Com esta pesquisa, foi possível perceber o design gráfico como um elemento mediador de significações diretamente impactantes no contexto social, cultural e econômico. Além disso, foi compreendido que esta área de atuação não diz respeito somente a imagens e textos e que tampouco está vinculada apenas à indústria, ao consumo ou à estética. 0 design participa da cultura, da criação e transmissão de idéias, das emoções, dos sentimentos, das identidades e das transformações do mundo em que se vive. Logo, fazer e discutir o design deve significar, necessariamente, construir e debater a sociedade como um todo. 
As grandes marcas na pequena Parintins:

Um estudo sobre a adaptação do discurso da marca

global ao regional como estratégia de comunicação

\section{Referências Bibliográficas}

> CASTELLS, Manuel. 0 poder da identidade. Lisboa: Fundação Calouste Gulbenkian, 2003.

> CAVALCANTI, Maria Laura Viveiros de Castro. 0 Boi-Bumbá de Parintins, Amazonas: breve história e etnografia da festa. Hist. cienc. saude-Manguinhos [online]. 2000.

> COSTA, Joan. A imagem da marca: um fenômeno social. São Paulo: Rosari, 2008.

> FORTY, Adrian. Objetos de desejo: design e sociedade desde 1750. São Paulo: Cosac at Naify, 2007.

> GARCIA CANCLINI, Nestor. A globalização imaginada. São Paulo: Iluminuras, 2007.

> HALL, Stuart. A identidade cultural na pós-modernidade. 6. ed. . Rio de Janeiro: DP\&A, 2006.

> HARVEY, David. A condição pós-moderna: uma pesquisa sobre as origens da mudança cultural. 4.ed. São Paulo: Loyola, 1994.

> KLEIN, Naomi. Sem logo: a tirania das marcas em um planeta vendido. 6. ed. Rio de Janeiro: Record, 2003.

> SCHNEIDER, Beat. Design - uma Introdução: o design no contexto social, cultural e econômico. São Paulo: Blucher, 2010.

> SEMPRINI, Andrea. A marca pós-moderna: poder e fragilidade da marca na sociedade contemporânea. São Paulo: Estação das Letras, 2006.

> VILLAS-BOAS, André. Identidade e cultura. Rio de Janeiro: 2AB, 2002.

Rafaela Claudia Sotuyo, Universidade do Estado de Santa Catarina, ex-aluna do curso de Bacharelado em Design Gráfico.

rafaelasotuyo@gmail.com

Gabriela B. Mager, Universidade do Estado de Santa Catarina, professora do Departamento de Design.

gabriela@th.com.br 